\section{Animal procedures research}

SIR-I am writing in my capacity as chairman of the research subcommittee of the Animal Procedures Committee about the new Home Office scheme to support research that could lead to a reduction, refinement or replacement of the use of living animals for experimental or other scientific purposes. The Animal Procedures Committee advises the Home Office on the priorities for such research and assists in the selection and evaluation of proposals.

The use of living animals in scientific procedures is an emotive issue that raises a number of ethical questions. There is considerable public awareness and concern about the purposes of many procedures and how they are carried out, which is often heightened by misleading reporting. However, the fact remains that regrettably the use of animals continues to be needed in many areas of research work and safety testing. It is of course incumbent upon those working in biomedical research to ensure that they use animals only where no suitable alternative exists, that they use the minimum number of animals necessary and that no avoidable

\section{Fraudulent slur}

SIR- "Scientific fraud" has for some time been debated in scientific journals and the popular press on both sides of the Atlantic, usually in a cynical tone. Individual suspected cases have added grist to the mill $^{1,2}$. There is throughout an unstated but persistent assumption that individuals accused of scientific fraud are indeed guilty. There is something perverse in human nature that makes people pleased when respectable, prominent individuals are accused of wrongdoing. When this happens, the idea of giving someone the benefit of the doubt seems to disappear, as well as the concept of "innocent until proven guilty".

If anomalous data are found in the report(s) in question, error may have occurred in the typing/reviewing/editing process, instruments may have lacked calibration or been misread, a mistake made in cataloguing samples, or there may be misperception due to mental set. Individual lives may suffer as a result of mistakenly attributing fraud to a particular study.

I myself did a study as a graduate student that contained a number of errors ${ }^{3}$. They were due not to fraud but to sloppy editing/paperwork on my part. I have not been accused of scientific fraud, probably because of the study's insignificance.

Essentially, it was a simple study in social psychology. A car was parked by the side of the road between towns, with suffering is caused. These principles are enshrined in the Animals (Scientific Procedures) Act 1986, which imposes strict controls on the use of living animals in scientific procedures.

Much work is already being done by charitable bodies and commercial concerns to find alternatives to the use of living animals. But it is important that those involved in research work and safety testing are not only involved but are seen to be involved in seeking alternatives.

I am pleased to announce therefore that limited funds will be available from April 1991 for research in the United Kingdom into the reduction, refinement or replacement of the use of living animals in scientific procedures. The Animal Procedures Committee will give preference to research proposals that have a good prospect of leading to the refinement or replacement of procedures which use large numbers of animals or which involve substantial suffering, for example challenge tests and vaccine production. The committee also continues to be interested in the possi bility of developing better measures of disease, discomfort and stress in labora-

the hood up to signify car trouble. A man or a woman would stand by the car and the number of vehicles stopping to offer assistance was tabulated. Simple. To no one's surprise, the overwhelming offers of assistance were offered to the woman.

The dumb mistakes in the paper occurred in citing references in the text that were forgotten in the reference section, and, when in calculating the $\chi^{2}$, the wrong column in the significance table was read, so that instead of $P \leqslant 0.001$ it was in reality $P \leqslant 0.01$.

Ironically, the one detail in the paper that looked suspicious did indeed occur. Over several hours, exactly the same number of other vehicles passed by the car for each participant.

Now, I can't help wondering if some of the serious accusations of scientific fraud bandied about are not due to similar embarrassingly simple, yet stupid mistakes. In one recent case involving AIDS research, in fact, the accused individual said the resulting uproar was "due to sloppy paper-writing in a tense period" (of competition $)^{4}$. At the same time, it is also true that some other anomalous reports have been widely acknowledged to be due to "honest mistakes", and not to fraud".

4453 Salvia Drive, ARMANDO SIMÓN

Orlando, Florida 32809-3151, USA

Anderson, C. Nature 347,317(1990)

. Jayaraman, K. S. Nature 347, 318 (1990)

3. Simón, A. Psycholo. Rep. 39, 883-886 (1976).

Anderson, C., Concar, D. \& Anderson, A. Nature 347, 502 (1990)

5. Maddox, J. Nature 347, 411 (1990) tory animals, and in improvements in the husbandry of such animals. Grants will normally be awarded for periods up to three years.

Details of the research scheme and how to apply may be obtained from Mr Peter Edmundson, E Division, Room 971, Home Office, 50 Queen Anne's Gate, London SW1H 9AT - (071 273 2029). Completed applications will be considered in the first half of April this year.

Animal Procedures Committee ANDREW HUXLEY

50 Queen Anne's Gate,

London SW1H 9AT, UK

\section{German education}

SrR-Steven Dickman is correct to claim (Nature 348, 187; 1990) that university entrance standards in West Germany were generally relaxed in the $1960 \mathrm{~s}$, enabling more than a quarter of the age group concerned to attend university. This process has been welcomed by some and criticized by many others. But the assertion that East Germany selected its students much more strictly needs clarification.

In both parts of Germany, the gateway to university is the Abitur encompassing a number of oral and written examinations. In West Germany, any high-school student meeting the necessary academic requirements was granted the opportunity to reach his goal, but pupils in East Germany were selected by criteria only partly connected with their personal scholarly abilities. In fact, these criteria included socialist achievements as well as the political and social status of the pupil's parents, pupils from working-class families being preferred to those from parents with an academic background. As the headmaster of a school could make the final decision as to which of the pupils could continue towards the Abitur, many were not given this opportunity because of personal dislike, even though they met the necessary academic requirements. Others passed with comparatively low qualifications, as the quality of the teaching staff was measured by the number of pass grades among their own students.

Being myself a future student of medicine, it is painful to be once again faced with the myth of the superior East German student. In contrast, many school-leavers in East Germany were forced to do a manual job rather than being given the opportunity to study at university.

Saldernstrasse 22,

TOM J. WEBER

3000 Hannover 71 , Germany

Letters submitted for Correspondence should be typed, double-spaced, on one side of the paper only. 